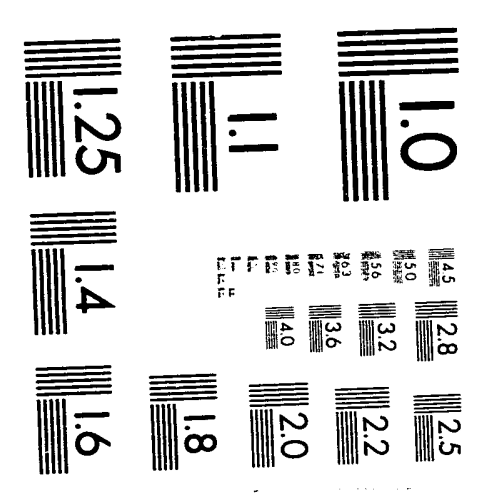



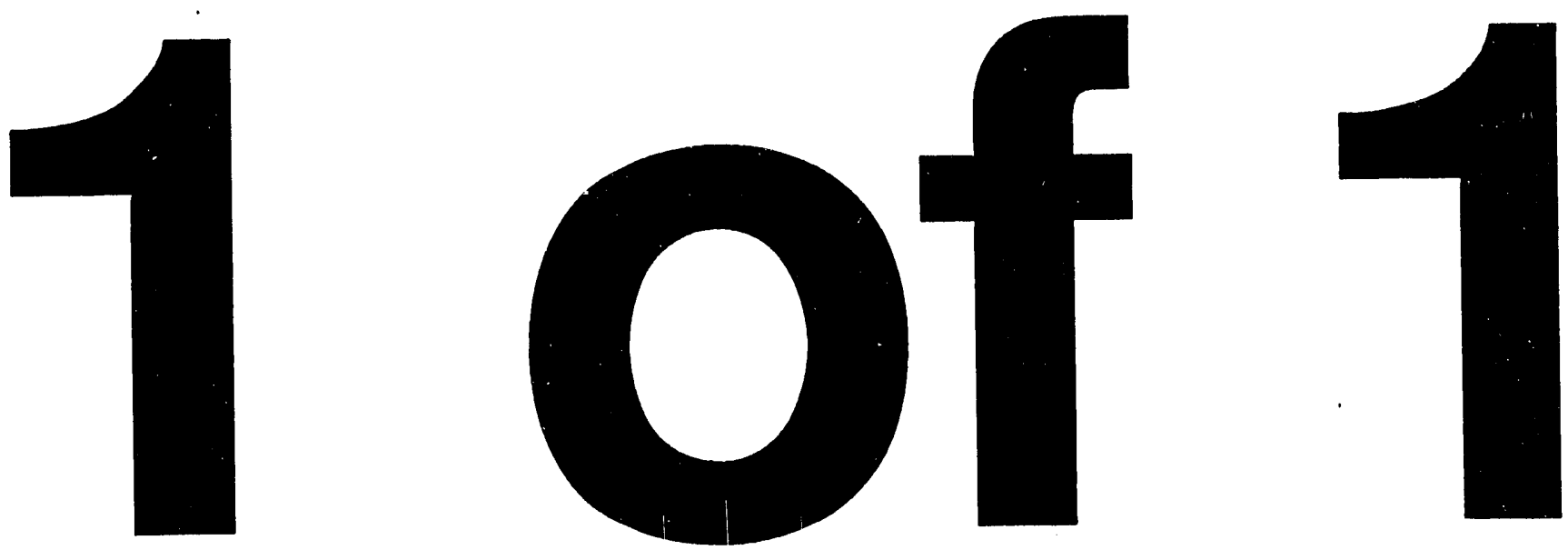


\title{
High Speed Data Acquisition for the High Pressure Laboratory
}

\author{
G. Koide \\ University of Hawaii, Hilo Campus, HI
}

T.R. Metz

Lawrence Livermore National Laboratory, Livermore, CA

July, 1993

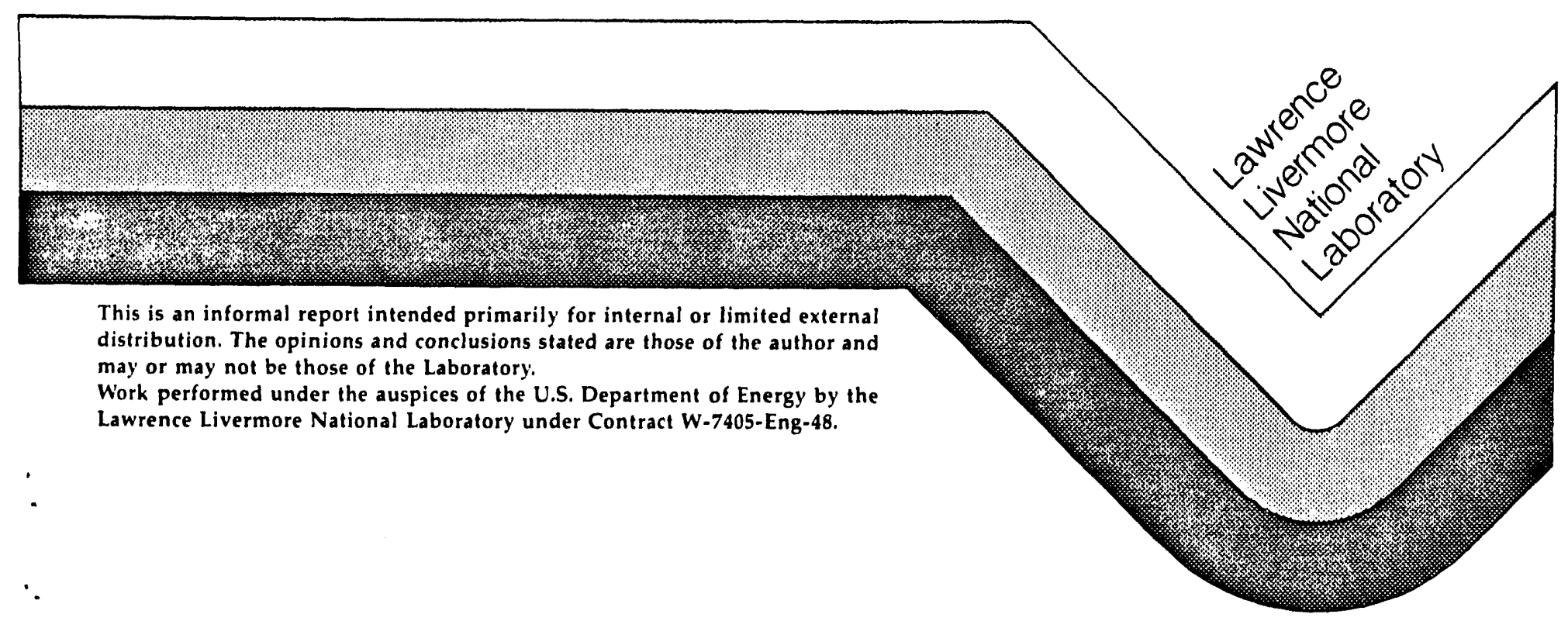




\section{Disclaimer}

This document was prepared as an individual account of work accomplished by the authors in response to certain needs and interests expressed by an agency of the United States Government. Neither the United States Government nor the University of California nor any of their employees makes any warranty, expressed or implied, or assumes any legal liability or responsibility for the accuracy, completeness, or usefulness of any information, apparatus, product, or process disclosed, or represents that its use would not infringe privately owned rights. Reference herein to any specific commercial products, process, or service by trade name manufacturer, or otherwise, does not necessarily constitute or imply its endorsement,

recommendation, or favoring by the United States Government or the University of California. The views and opinions of the authors expressed herein do not necessarily state or reflect those of the United States Government or the University of Califormia and shall not be used for advertising or product endorsement purposes.

This report has been reproduced directly from the best available copy.

Available to DOE and DOE contractors from the Office of Scientific and Technical Irformation P. O. Box 62 Oak Ridge, TN 3783

Prices available from (615) 576-8401, FTS 626-8401

Available to the public from the National Technical Information Service

U.S. Department of Commerce 5285 Port Royal Rd. Springfield, VA 22161 


\section{Foreword}

by Jay Brentjes, Group Leader High Pressure Systems, LLNL

Dr. George Koide is presently a Professor of Engineering and Computer Science at the University of Hawaii at Hilo. He has been a consultant and was employed by LLNL while on sabbatical leave in 1988. During this time he became deeply involved in preparing software systems for computer controlled test equipment used in the High Pressure Laboratory (HPL) as well as writing software programs for computer aided design and drafting for the former Nuclear Explosive Engineering Division. As a result of his personal interest in preparing a software program for data acquisition routines used on a MacIntosh computer, he maintained a close liaison with individuals in HPL and formulated the programs which are described in this and an other referenced report. Tom Metz, a technologist at LLNL, worked closely with Dr. Koide and has adapted the programs for use in the High Pressure Laboratory.

I would like to extend a personal note of thanks to Dr. Koide and Tom and encourage the reader to contact the authors for further information regarding this unique and useful software program. It is worth noting that the data acquisition program may be readily adapted to other test systems which have transducer outputs and require a real time display of data. 


\begin{abstract}
A menu driven 16-bit data acquisition system has been developed to accept data at a maximum rate of two thousand samples per second. With a maximum of eight separate channels, calibrated prior to running a test, real-time plots are shown on the monitor as data are stored on the hard disk. After an experimental run, hard copies may be obtained with a plotter by running a separate program called Graph.
\end{abstract}




\section{Table of Contents}

Page

$\begin{array}{llr} & \text { Abstract } & 4 \\ & \text { Table of Contents } & 5 \\ \text { I } & \text { Introduction } & 6 \\ \text { II } & \text { Hardware } & 6 \\ \text { III } & \text { Software } & 6 \\ & \text { A. Main Menu } & 6 \\ & \text { B. Calibration of Transducer } & 7 \\ & \text { C. Running the Test } & 8 \\ \text { IV } & \text { Summary } & 8 \\ \text { V } & \text { References } & 9\end{array}$

Page 5 


\section{Introduction:}

Software for a sixteen-bit data acquisition system has been developed for the Macintosh computers. With a maximum of eight channels, a user can obtain data at a maximum rate of two thousand samples per second. In addition, realtime plots allow the experimenter to observe the current status of any test. After a test, post-experimental plots are available for an experimenter to obtain hard copies.

The software is menu driven which permits the user to backtrack or quit anytime. There are three main sections, the main menu, calibration of the transducers, and running the test. In each of these sections, a user is able to return to the previous section, allowing the operator to re-check any previous task by going back and redoing it.

After a test another program, Graph, must be run to produce hard copies on a plotter. Multiple channels, single channel, or any combination of channels may be drawn. Finally telescopic views of specific portions of the graph permits the experimenter to analyze the data more closely. See Reference 1 for details.

\section{A/D Hardware:}

To use this software, a NB-MIO-16XL or a NB-MIO-16XH analog board built by National Instruments must be installed in the MacIntosh computer. These are the sixteen bit analog-to-digital converter boards configured in a differential mode input with eight channels. The NB-MIO-16XL board is a high level input board with voltage gains of 1,10,100 and 500 while the NB-MIO$16 \mathrm{XH}$ board is a high level input board with gains of $1,2,4$ and 8 . Because the gain is set to 1 , only high level signals should be used. The range of input voltage for each channel must be between -10 and +10 volts. Moreover, since DMA is used, a NB-DMA-8-G dma board must be part of this computer system.

\section{Software:}

The user selects the "Data Acquisition 16-Bit" project to activate the high speed data acquisition system. Then the parameters of the main menu are entered followed by the calibration of the transducers. Lastly the data acquisition starts real-time plots and stores data.

\section{A. Main Menu:}

The three main sections for the user are (1) the main menu, (2) calibration of the transducers, and (3) running a test. In the main menu, see Figure 1, the operator must enter the essential parameters of the test which are: (1) title of the test, (2) name of experimenter, (3) name of operator, (4) number of channels, 
(5) sampling rate in data points per second, and (6) A/D board slot number. Figure 1 shows the main menu.

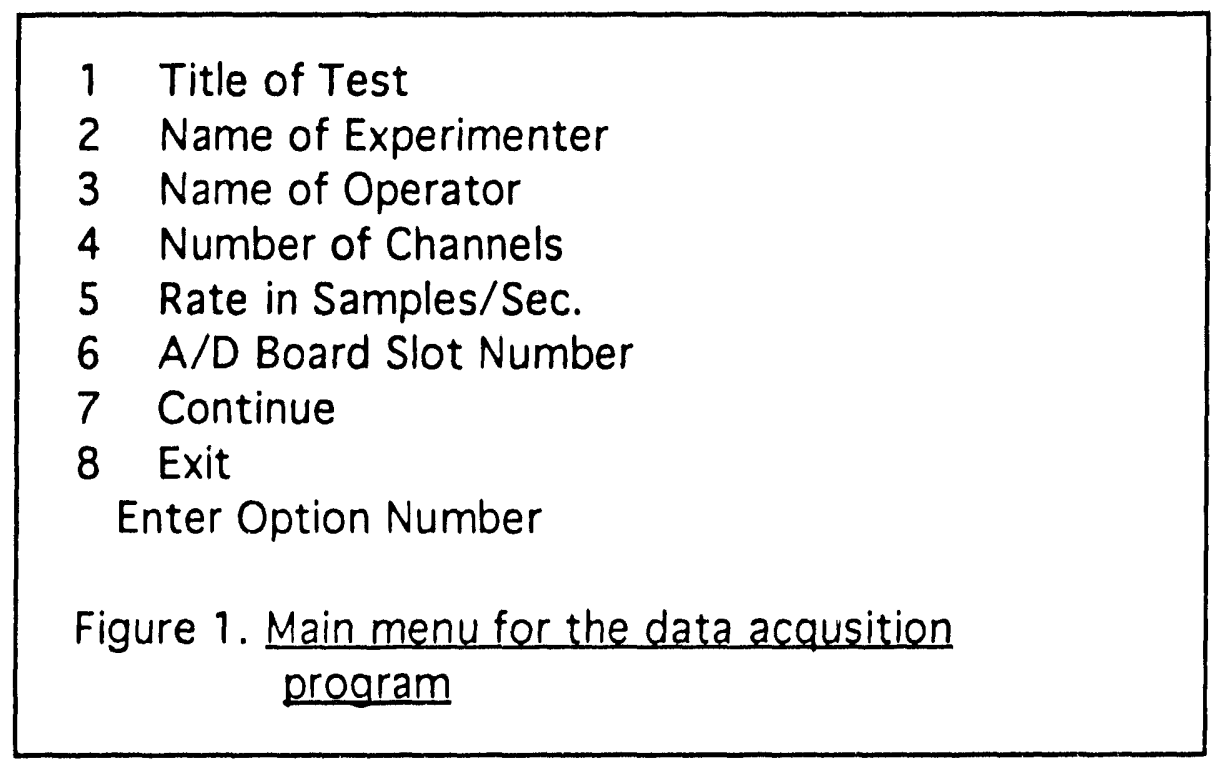

Since the A/D board occupies a specific slot on the mother board, the user must know its location before running a test. In the main menu, the operator enters the correct slot number which National Instrument requires for their A/D drivers.

For a sampling rate less than 100, the real-time plots are updated every two seconds. For faster sampling rates, the real-time plots are updated at approximately once every one to two seconds. At these rates, the real-time plots are just samples of the data being collected. How'ver, the post-experimental plots use the entire data set.

\section{B. Calibration of Transducers:}

The A/D board should be configured to accept signals in the differential mode. Because the gain is set to one by software, a high level input signal to the $A / D$ board is required. The range of voltage for the differential mode is between -10 to +10 volts.

The transducers must be in sequential order starting with channel number zero which is one of the software requirements. Also each channel is calibrated chronologically with channel zero. For each calibration, the physical units for the transducer must be entered. Then two distinct known points must be entered. These inputs could be simulated by using a shunt calibration, i.e. for the first input the transducer is at its resting or initial value and for the second input a shunt resistor in a Wheatstone bridge configuration simulates the known value of the transducer. 
After all of the transducers have been calibrated, a summary menu is displayed. If any of the transducers must be re-calibrated, the user may select that particular channel. An example of the summary menu is shown in Figure 2 which shows two transducers.

\section{Pressure in PSIG \\ 1 Temperature in Centigrade \\ 2 Continue \\ 3 Return to previous menu \\ 4 Exit}

Enter Option Number

Figure 2. Summary of calibration of transducers.

\section{Running a Test:}

After the transducers have been calibrated, the real-time plot grid lines are constructed. Then the user presses the "B" key (for begin) to start the data acquisition. If the sampling rate is greater than 100 , the real-time plots are updated about one to two seconds. Otherwise it is updated every two seconds. To end the test, the operator presses the " $E$ " key for end. When the letter " $E$ " is pressed, a message to stop the test is displayed. Only when the user presses " $Y$ " (for yes) will the data acquisition be terminated. Otherwise the data acquisition will continue. This protects the operator from accidentally pressing the end key and stop the test.

While the test is running, it can restarted by the operator by pressing the "R" key. When this option is chosen all data that have been collected will be lost. Then the program returns to display the summary of the calibration of transducers.

\section{Summary}

An experimenter can acquire data at a maximum rate of 2000 samples per second. While the test is running, the operator monitors it by observing the realtime plots. After the test, a post-experimental plot program is run for the customer to obtain hard copies. A maximum of eight channels are available for the user. 


\section{References}

1. G. Koide, T. Metz, "Post-Experimental Plots for High Speed Data Acquisition Program", UCRL-ID-114808, July 1993.

2. "LabView 2, Operations Manuals", National Instruments, February 1992 Edition. 

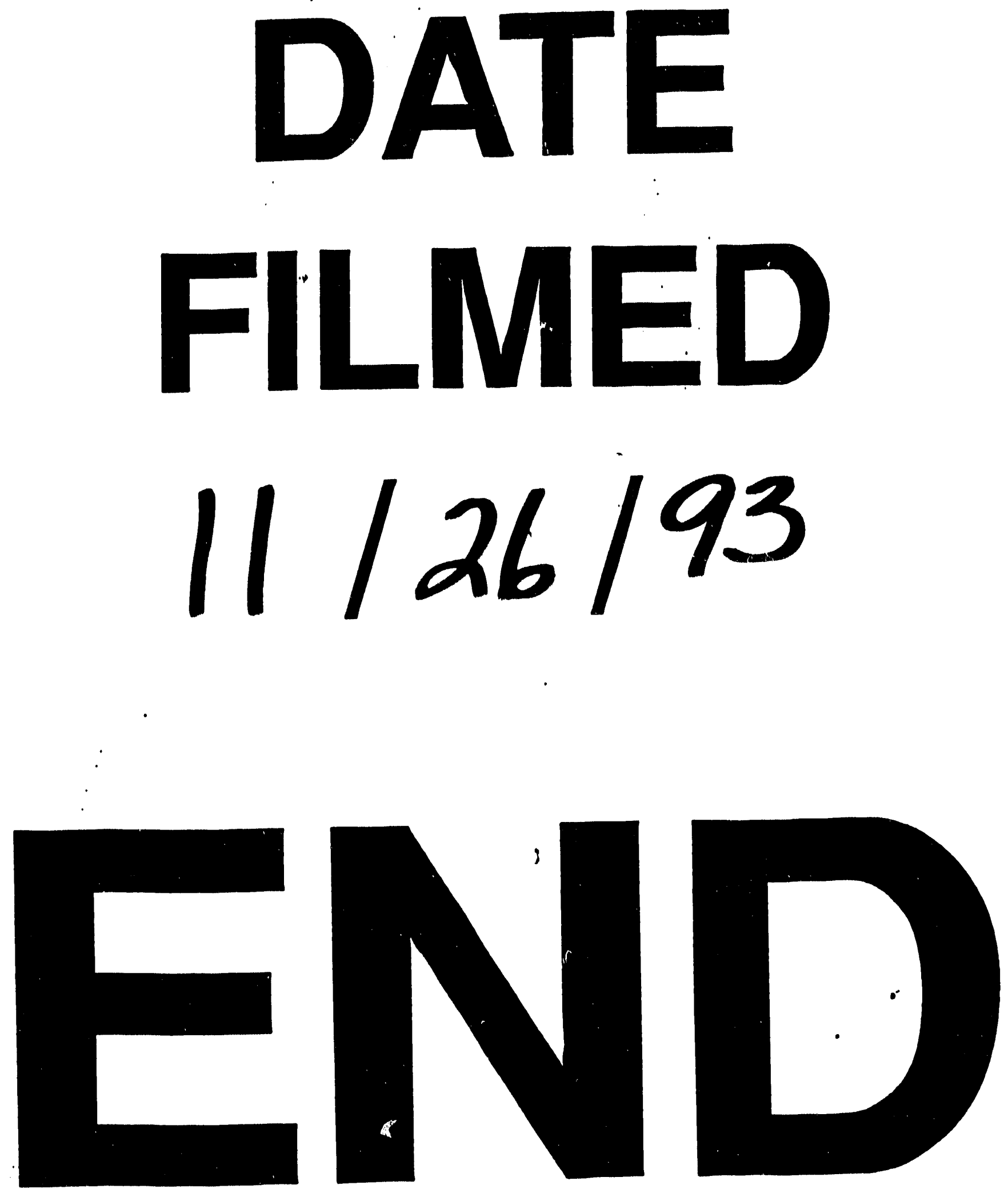


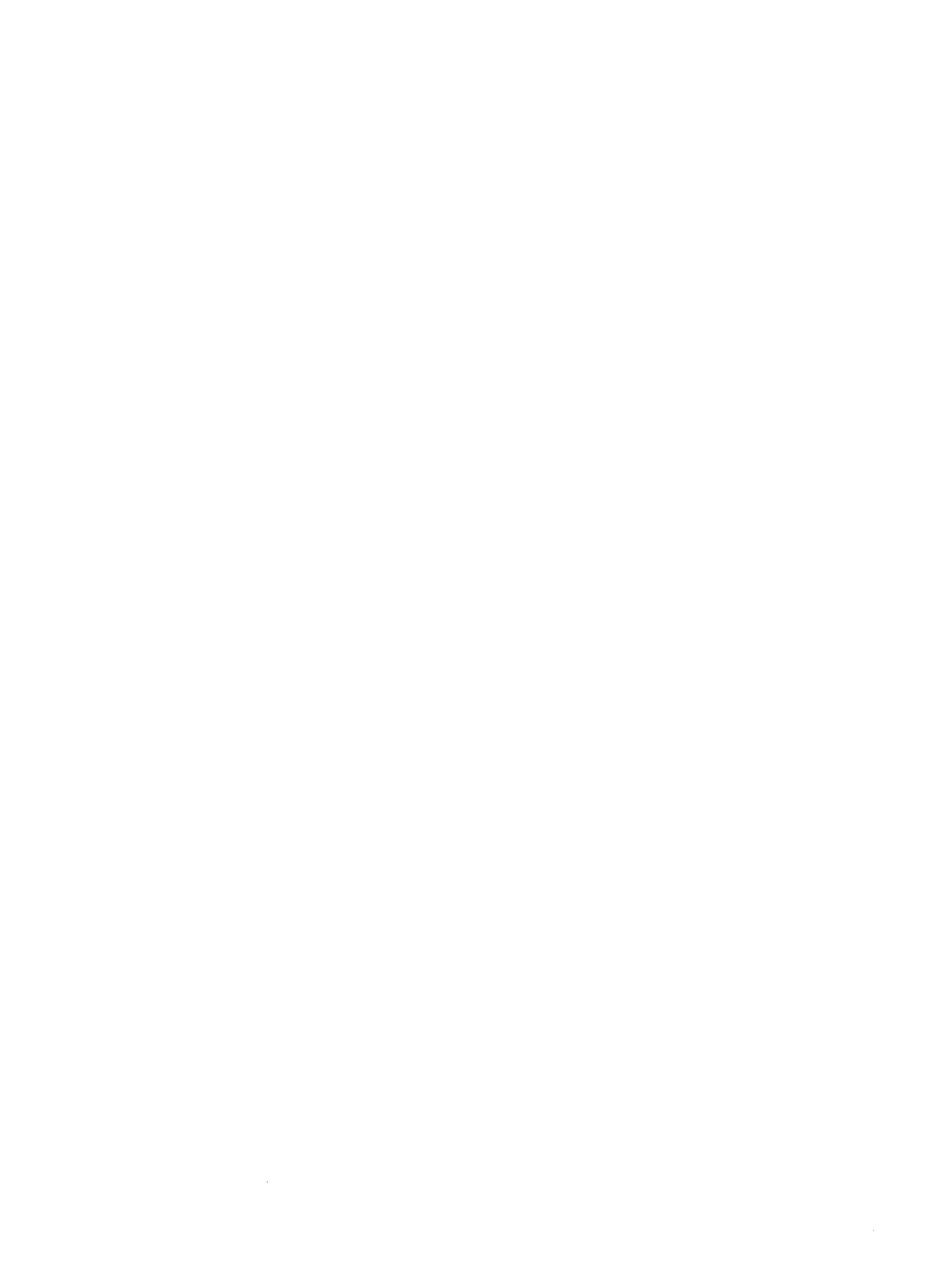

